\title{
A clinico-microbiological study of diabetic foot ulcer patients to identify risk factors and their correlation with prognosis in tertiary care hospital in India
}

\section{Arun Anand 1 , Indu Biswal ${ }^{2}$, Rajesh Kumar Soni ${ }^{1}$, Ajit Sinha ${ }^{1}$, Dabet Rynga ${ }^{2}$, Manorama Deb $^{2}$}

\author{
${ }^{1}$ Department of Surgery, ${ }^{2}$ Department of Microbiology, VMMC and Safdarjung Hospital, New Delhi, India
}

Received: 15 January 2016

Accepted: 17 February 2016

*Correspondence:

Dr. Rajesh Kumar Soni

E-mail: sonirajesh79@yahoo.co.in

Copyright: () the author(s), publisher and licensee Medip Academy. This is an open-access article distributed under the terms of the Creative Commons Attribution Non-Commercial License, which permits unrestricted non-commercial use, distribution, and reproduction in any medium, provided the original work is properly cited.

\section{ABSTRACT}

Background: The number of diabetics in India is rising very fast and foot ulcer patients are consuming lot of hospital resources and manpower. Foot infection, leading to ulcer formation eventually leading to amputation, is totally preventable. Few studies have been done in India to predict risk factors. We studied the clinico-microbiological profile of diabetic foot ulcer patients to correlate prognosis and to identify patients who are at increased risk of amputation.

Methods: 50 diabetic foot patients were assessed for age, sex, clinical presentation and routine haematological investigations. Ulcer characteristics were determined based on Wagner's classification. Tissue samples from these patients were also cultured for infection. We studied various factors affecting healing of ulcers. We also tried to find factors predicting the need of amputation in these patients.

Results: The mean age of the patients was 52.42 years. The male: female ratio is $3.5: 1$. The WAGNER grade of III was seen in $48 \%$ of the patients, grade I in $16 \%$, grade II in $14 \%$, grade IV in $14 \%$ and grade V in $8 \% .100 \%$ of the patients with grade IV and V underwent amputation, while $8.3 \%$ with grade III and $4.16 \%$ with grade II had to undergo amputation and none with grade I had to receive amputation. Sixty-eight percent of these patients had been diagnosed with Diabetes for less than 10 years while the rest have been diagnosed for more than 10 years. $60 \%$ of patients were found to have peripheral neuropathy out of which $40 \%$ were sensory type and the rest were motor type. Proteus mirabilis was isolated in $80 \%$ of the patients who underwent amputation, Streptococcus pyogenes in $57 \%$, Pseudomonas aeruginosa (50\%), Klebsiella pneumonia (33\%), and Staphylococcus aureus (12\%).

Conclusions: This study showed that male sex, smoking, above 50 years age, neuropathy and infection with Gram negative organisms are important predicting factors for developing severe foot infection in diabetics, often leading to amputation. There is a need for developing a risk assessment model in a larger prospective cohort study.

Keywords: Diabetic foot, Diabetic foot ulcer, Diabetic foot infection, Diabetic foot amputation.

\section{INTRODUCTION}

Diabetic foot syndrome (DFS) is a complex and heterogeneous disorder that affects $15 \%$ of patients with diabetes during their lifetime. According to epidemiological studies, the number of patients with diabetes mellitus (DM) increased from about 30 million cases in 1985, 177 million in 2000, 285 million in 2010, and it is estimated that if the situation continues, more than 360 million people by 2030 will have DM. It is estimated that approximately $20 \%$ of hospital admissions among patients with DM are the result of DFS. In India, prevalence of diabetic foot ulcers is $3.6 \%$. The novel project 'Step- by- Step Improving diabetes Foot care in 
the developing world' was initiated in India, with the goal to train health care providers with basic foot care and give them hands on experience in treatment of trivial foot lesions. Ischaemia, neuropathy, and infection are the three cardinal aetiological factors predisposing to diabetic foot ulcers. Diabetic foot infections may be extremely challenging to cure, due to late diagnosis (due to blunted clinical signs), presence of ischaemia, difficult to-treat multidrug-resistant pathogens, and spread of infection to the bones, leading to osteomyelitis. This study was conducted with the aim to determine the clinical and microbiological profile of diabetic foot patients and to assess their outcome. ${ }^{1-8}$

\section{METHODS}

\section{Study design, setting and sample}

The present study was a cross sectional study, conducted in the department of surgery and microbiology at Vardhman Mahavir medical college and Safdarjang hospital, New Delhi, India, over a period of 18 months during 2012-13. The study included a total of 50 adult patients of clinically diagnosed diabetic foot patients presenting to outpatient department and emergency ward. The standard case definition of diabetic foot is 'any pathology occurring in the foot of a patient suffering from diabetes mellitus or as a result of long term complication of diabetes mellitus'. Samples were taken from enrolled subjects using the following criteria: patient with diabetic foot pathology. All patients signed an informed consent and the study was approved by the ethical committee of the hospital.

\section{Clinical factors}

The factors namely age, sex, clinical signs and symptoms, risk factors, radiological findings and routine haematological investigations were recorded. Ulcer size, including surface area, depth, and extent of spread was measured using Wagner's classification as shown in (Table 1). ${ }^{9}$

Table 1: Wagner's classification in diabetic foot patients.

\begin{tabular}{|ll|}
\hline Grade & Clinical signs \\
\hline 0 & Intact skin \\
\hline 1 & Superficial ulcer of skin/ subcutaneous tissue \\
\hline 2 & Ulcer extending to tendon/ bone/ capsule \\
\hline 3 & Deep ulcer with osteomyelitis/ abscess \\
\hline 4 & Gangrene of toes/ forefoot/ localized gangrene \\
\hline 5 & Mid foot/ hind foot gangrene \\
\hline
\end{tabular}

\section{Microbiological cultures}

Tissue samples from the ulcer site were obtained from these 50 patients and processed for culture. Quantitative tissue cultures were performed using standardized procedures. Tissue specimens were weighed, homogenized and diluted with $5 \mathrm{ml}$ of peptone water. Serial dilutions to 10 were made with $0.85 \% \mathrm{NaCl}$, and $0.1 \mathrm{ml}$ of each dilution was plated onto $10 \%$ sheep blood agar and MacConkey agar and then incubated at $37^{\circ} \mathrm{C}$ overnight. Identification of organism was done by conventional methods. ${ }^{4,10,11}$

\section{Statistical analysis}

The results were analyzed using the Chi-square tests. A 'P' value of less than 0.05 was taken as significant.

\section{RESULTS}

The mean age of the patients was 52.42 years. The demographic profile, risk factors and clinical presentation of the patients is shown in (Table 2). Out of 50 patients, the highest number of patients was in the older age group of 51-60 years old of $34 \%$ (17/50). The male: female ratio is 3.5:1. Sixty-eight percent (34/50) of these patients had been diagnosed with diabetes for less than 10 years while the rest have been diagnosed for more than 10 years.

Table 2: Demographic Profile, risk factors and clinical presentation of $\mathbf{5 0}$ diabetic foot patients included in the study.

\begin{tabular}{|lll|}
\hline Profile & No of patients & Percentage \\
\hline Age Group & & \\
\hline 21-30 years & 4 & $8 \%$ \\
\hline 31-40 years & 6 & $12 \%$ \\
\hline 41-50 years & 11 & $22 \%$ \\
\hline $51-60$ years & 17 & $34 \%$ \\
\hline $61-70$ years & 10 & $20 \%$ \\
\hline $71-80$ years & 2 & $4 \%$ \\
\hline Sex & & \\
\hline Male & 39 & $78 \%$ \\
\hline Female & 11 & $22 \%$ \\
\hline Risk factors & & \\
\hline Trauma & 31 & $62 \%$ \\
\hline Smoking & 15 & $30 \%$ \\
\hline Family history of diabetes & 6 & $12 \%$ \\
\hline
\end{tabular}

On examination, $60 \%(30 / 50)$ were found to have peripheral neuropathy out of which $40 \%$ (20/50) were sensory type and the rest were motor type. The Wagner grade of III was seen in $48 \%(24 / 50)$ of the patients, grade I in $16 \%(8 / 50)$, grade II in $14 \%(7 / 50)$, grade IV in $14 \%(7 / 50$ and grade $\mathrm{V}$ in $8 \%$ (4/50). On Doppler, $38 \%$ (19/50) were found to have PVD and on X-Ray, $42 \%$ $(21 / 50)$ of the patient revealed to be normal, $24 \%(12 / 50)$ had osteomyelitis, $8 \%(4 / 50)$ had Charcot's joint, $4 \%$ $(2 / 50)$ has osteoporosis and $2 \%(1 / 50)$ had a fracture. $60 \%(30 / 50)$ of the patients were anaemic with haemoglobin levels of less than 10 gram $\%$ and this was more commonly seen in women than in men. 
Eighty percent (40/50) of the patients in this study were surgically treated by debridement, $26 \%$ (13/50) by amputation, $12 \%(6 / 50)$ by incision and drainage and the rest $16 \%(8 / 50)$ were conservatively treated.

When comparing the Wagner grade, $100 \%$ of the patients with grade IV (7/7) and V (4/4) underwent amputation, while $8.3 \%$ with grade III $(1 / 24)$ and $4.16 \%$ with grade II (1/7) had to undergo amputation and none with grade I had to receive amputation. When comparing the patients with neuropathy, $26.67 \%(8 / 30)$ of them underwent amputation while $25 \%(5 / 20)$ of those without neuropathy also underwent amputation. Similarly, 31\% (6/19) of those with vasculopathy underwent amputation while $22.5 \%(7 / 31)$ of those without vasculopathy were amputated.

The bacteriological distribution of 42 of the 50 study patients is represented in (Table 3 ).
Table 3: Distribution of the bacterial isolation from $\mathbf{5 0}$ diabetic foot patients included in the study.

\begin{tabular}{|lll|}
\hline $\begin{array}{l}\text { Organisms grown in } \\
\text { culture }\end{array}$ & $\begin{array}{l}\text { No. of } \\
\text { isolates }\end{array}$ & Percentage \\
\hline Staphylococcus aureus & 16 & $38 \%$ \\
\hline Streptococcus pyogenes & 7 & $17 \%$ \\
\hline Klebsiella pneumonia & 6 & $14 \%$ \\
\hline Proteus mirabilis & 5 & $12 \%$ \\
\hline Pseudomonas aeruginosa & 2 & $5 \%$ \\
\hline No growth & 6 & $14 \%$ \\
\hline
\end{tabular}

On comparison of the bacterial isolate with the incident of amputation it was observed that $80 \%$ (4/5) of the patients in with Proteus mirabilis was isolated underwent amputation, $57.12 \%$ (4/7) with Streptococcus pyogenes, $50 \%(1 / 2)$ with Pseudomonas aeruginosa, 33.3\% (2/6) with Klebsiella pneumonia, $12 \% \quad(2 / 16)$ with Staphylococcus aureus underwent amputation. The associations of amputation with the various factors are shown in (Table 4).

Table 4: Association of amputation in patients with the various factors.

\begin{tabular}{|llcc|}
\hline Factors & No. of patients & No. of patients with amputation & Percentage \\
\hline Neuropathy & 30 & 8 & $26.67 \%$ \\
\hline Vasculopathy & 19 & 6 & $31.5 \%$ \\
\hline WAGNER Grade & & & $0 \%$ \\
\hline Grade I & 8 & 0 & $4.16 \%$ \\
\hline Grade II & 7 & 1 & $8.3 \%$ \\
\hline Grade III & 24 & 1 & $100 \%$ \\
\hline Grade IV & 7 & 7 & $100 \%$ \\
\hline Grade V & 4 & 4 & $80 \%$ \\
\hline Wound site infections with & & & $57.12 \%$ \\
\hline Proteus mirabilis & 5 & 4 & $50 \%$ \\
\hline Streptococcus pyogenes & 7 & 4 & $33.3 \%$ \\
\hline Pseudomonas aeruginosa & 2 & 1 & $12.5 \%$ \\
\hline Klebsiella pneumonia & 6 & 2 & 2 \\
\hline Staphylococcus aureus & 16 & & \\
\hline
\end{tabular}

\section{DISCUSSION}

This is a prospective study from Indian subcontinent to report on diabetic foot ulcers and their correlation with patient characteristics, clinical factors and microbiological diversity. The etiology of chronic wounds commonly relates to underlying pathologies. The initiation of the wounds is often associated with primary tissue damage, which creates a portal of entry for microorganisms and infection may occur. Wound infection is commonly defined according to the presence of pathogens and colonization densities exceeding $\geq 106$ organisms per gram of tissue and the development of significant tissue damage and clinical signs of infection. $^{12,13}$
In the present study, 50 patients were studied for over a period of 18 months. The demographics and patient characteristics have been described in (Table 2). The most common age presentation of the study subjects was 50-60 years, with a mean age of 52.42 years. This is in similar to the study conducted by Zaine et al, conducted in Sydney and Gardner et al, from Iowa where mean age of the study participants was 67 years and 64.2 years. Increasing age may be a contributory factor to chronic wounds as the skin can easily damage. Older cells do not proliferate as fast and may not have an adequate response to stress in terms of gene up regulation of stress related proteins. ${ }^{14-16}$ 
The male to female ratio in the present study is $3.5: 1$, with male predominance at $78 \%(39 / 50)$. This is comparable to the study conducted by Perrin et al from Victoria, where they reported male predominance at $61.3 \%$. The reason for this male predominance is unknown, although in Indian subcontinent, habit of bare foot walking and predominantly rural background may contribute to trauma leading to ulcers. Indians also sit with legs crossed for long hours of work or worship leading to repetitive, prolonged pressure over lateral malleolar areas, leading to bursae and dark hypertrophied skin, which can ulcerate and cause infection. ${ }^{17}$

The progression and chronicity of wounds can be correlated with duration of diabetes mellitus, where gradual alteration of host immune response makes even a slight trauma prone to ulcer formation and infection with pathogens. In this study, the mean duration of diabetes in patients was 7 years. This is lesser than the study by Bassman et al, where mean duration of diabetes was 13 years. The patients presented with a varied range of symptoms like wound (84\%), discharge (56\%), swelling $(50 \%)$, pain $(40 \%)$, discoloration $(28 \%)$ and numbness (20\%). Most of the patients presented with more than one symptom. $^{18}$

In the present study, trauma was the most common risk factor present in $62 \%$ of the patients, followed by smoking (30\%). Six percent of the patients had previous episodes of amputation. This high prevalence of trauma history may be due to barefoot walking, outdoor activities and wrong foot wear. This is in contrast to the study by Zaine et al, where smoking emerged as a strong risk factor for peripheral arterial disease leading to foot ulcers. Other co-morbidities like neuropathy, anaemia and vasculopathy also predisposed the patient to diabetic foot ulcers. Neuropathy was found in $60 \%$ patients, followed by anaemia in $60 \%$ patients and vasculopathy (38\%). The Eurodale studies highlighted peripheral arterial disease (49\%) and neuropathy (86\%) as two major risk factors of diabetic foot ulcerations. All the patients were given a thorough neurological examination with clinical interpretation using vibration sensation, proprioception, pin prick, temperature, reflexes and muscle weakness. These tests are easier to administer, less time consuming and cost effective. ${ }^{14,19}$

In the present study, culture positivity was found to be $84 \%$, out of which $46 \%$ were gram positive flora. Among the gram positive organisms, Staphylococcus aureus was found in $16(32 \%)$, followed by Streptococcus sp. in 7 $(14 \%)$. Similar findings were observed by Gardner et al, where they found predominance of Staphylococcus $(40 \%)$ and Streptococcus $(37 \%)$ in diabetic foot ulcers. Microbial load is widely viewed as the reference standard for determining the bio burden in chronic wounds. However, cultures under-represent the microbial load of the ulcer as compared with 16SrRNA gene approaches. Unfortunately, gene sequencing was not done in the current study which remains the limitation of the study. ${ }^{15}$
We also tried to find factors predicting the need of amputation in these patients, which is represented in the (Table 4). Vasculopathy and neuropathy were major contributors to amputation in such patients found in $31.5 \%$ and $26.6 \%$ respectively. The patients were graded under Wagner classification for diabetic foot at the time of presentation and after 6 weeks. $48 \%$ patients presented with grade III followed by $16 \%$ with grade I at the time of presentation. However there was a shift in the grading with $84 \%$ presenting with grade 0 and $16 \%$ presenting with grade II at 6 weeks. All patients with grade IV and $\mathrm{V}$ had worse prognosis and needed amputation. This is in contrast to the study done by Zaine et al, who used Pedis system to grade infected foot ulcers. Among their patients grade $2(21.5 \%)$ was most prevalent followed by grade 3 $(26.7 \%){ }^{14}$

Most of the patients needing amputation had a predominant gram negative micro biome, with growth of Proteus mirabilis and Pseudomonas aeruginosa in $80 \%$ and $50 \%$ respectively. Among gram positives, Streptococcus pyogenes was the most common isolated organism $(57 \%)$ in amputated patients.

There is paucity of information on predictive values of risk factors and microbial load of diabetic foot ulcers in the Indian health care system setting. Ours was a small study where we tried to correlate prognosis of diabetic foot ulcers with demographics, risk factors and microbial flora. There is a need for developing a risk assessment model in a larger prospective cohort study. This will enable clinicians to identify and estimate the patient co morbidities, clinical factors and risk factors associated with diabetic foot ulcers.

\section{CONCLUSION}

This study showed that male sex, smoking, above 50 years age, neuropathy and infection with Gram negative organisms are important predicting factors for developing severe foot infection in diabetics, often leading to amputation. There is a need for developing a risk assessment model in a larger prospective cohort study.

\section{Funding: No funding sources Conflict of interest: None declared \\ Ethical approval: The study was approved by the institutional ethics committee}

\section{REFERENCES}

1. Yazdanpanah L, Nasiri M, Adarvishi M. Literature review on the management of diabetic foot ulcer. World J Diabetes. 2015;6(1):37-53.

2. Shaw JE, Sicree RA, Zimmet PZ. Global estimates of the prevalence of diabetes for 2010 and 2030. Diabetes Res Clin Pract. 2010;87:4-14.

3. Whiting DR, Guariguata L, Weil C, Shaw J. IDF diabetes atlas: global estimates of the prevalence of 
diabetes for 2011 and 2030. Diabetes Res Clin Pract. 2011;94:311-21.

4. Snyder RJ, Hanft JR. Diabetic foot ulcers-effects on QOL, costs, and mortality and the role of standard wound care and advanced-care therapies. Ostomy Wound Manage. 2009;55:28-38.

5. Pendsey S. Reducing diabetic foot problems and limb amputation: an experience from India. 2005;15-20.

6. Papanas N, Maltezos E. The diabetic foot: a global threat and a huge challenge for Greece. Hippokratia. 2009;13(4):199-204.

7. Edmonds M. Modern treatment of infection and ischaemia to reduce major amputation in the diabetic foot. 2013;19(27):5008-15.

8. Arag'on-S'anchez J, Lipsky BA, L'azaro-Mart'inez BA. Gram-negative diabetic foot osteomyelitis: risk factors and clinical presentation. The International Journal of Lower Extremity Wounds. 2013;12(1):63-8.

9. Wagner FW. The diabetic foot. Orthopaedics. 1987;10:163-72.

10. Demetriou M, Papanas N, Panopoulou M, Papatheodotou K, Bounovas A, Maltezos E. Tissue and swab culture in diabetic foot infections: neuropathic versus neuroschaemic ulcers. The International Journal of Lower Extremity Wounds. 2013;12(2):87-93.

11. Miles RS, Amyes SGB. Laboratory control of antimicrobial therapy. In Collee JG, Fraser AG,
Marmion BP, Simmons A, editors. Mackie and McCartney practical medical microbiology: Churchill Livingstone, $14^{\text {th }}$ ed. Elsevier; 1996:131150.

12. Oates A, Bowling FL, Boulton AJM, McBaina AJ. Molecular and culture-based assessment of the microbial diversity of diabetic chronic foot wounds and contralateral skin sites. Journal of Clinical Microbiology. 2012;50(7):2263-71.

13. Robson MC. Wound infection: a failure of wound healing caused by an imbalance of bacteria. Surg. Clin. North Am.1997;77:637-50.

14. Zaine NH, Burns J, Vicaretti M, Fletcher JP, Begg L, Hitos K. Characteristics of diabetic foot ulcers in Western Sydney, Australia. Journal of Foot and Ankle Research. 2014;7:39.

15. Gardner SE, Hillis SL, Heilmann K, Segre JA, Grice EA. The neuropathic diabetic foot ulcer micro biome is associated with clinical factors. Diabetes. 2013;62(3):923-30.

16. Posnett J, Franks PJ. The burden of chronic wounds in the UK. Nurs Times. 2008;104:44-5.

17. Perrin B. A retrospective audit of a diabetic foot clinic. Australas J Podiatr Med. 2006;40:23-5.

18. Bassman et al. Vasculitis in Maturity onset Diabetes mellitus. JAMA.1976;235(23):2495.

19. Akhtar S, Schaper N, Apelqvist J, Jude E. A review of the Eurodiale studies: what lessons for diabetic foot care? Curr Diab Rep. 2011;11:1-8.

Cite this article as: Anand A, Biswal I, Soni RK, Sinha A, Rynga D, Deb M. A clinicomicrobiological study of diabetic foot ulcer patients to identify risk factors and their correlation with prognosis in tertiary care hospital in India. Int Surg J 2016;3:669-73. 